\title{
The FFC Cambridge Process for Production of Low Cost Titanium and Titanium Powders
}

\author{
Mark Bertolini ${ }^{1,}$ a , Lee Shaw ${ }^{1,}$ a, Lucy England ${ }^{1, a}$, Kartik Rao ${ }^{1,}$, , James \\ Deane $^{1, a}$ and James Collins ${ }^{1, a}$ \\ ${ }^{1}$ Metalysis Ltd., Rotherham, United Kingdom \\ ainfo@metalysis.com
}

Keywords: FFC Cambridge process, Titanium, Powder, Low cost, Metal Oxides, Alloys, Electrolysis, Powder Processes, Consolidation, Grinding, Gas Atomisation, Hydriding-GrindingDehydriding, Near Net Shape Manufacture.

\begin{abstract}
The current status and recent advancements in the use of the FFC Cambridge process for the production of low cost titanium and titanium powders is presented. This will include an overview of the process, current and future process equipment and recent results in terms of chemistry, structure and properties of powder and consolidated product. The future direction and activities for the FFC Cambridge process will also be briefly discussed.
\end{abstract}

\section{Introduction}

The FFC process is a patented technology capable of reducing a broad range of metal oxides to metals (Figure 1) and mixtures of metal oxides to alloys in a solid state process using electrolysis. In essence the technology involves immersing the oxide(s) to be reduced in a bath of electrolyte, typically molten calcium chloride at a temperature between $800^{\circ} \mathrm{C}$ and $1000^{\circ} \mathrm{C}$ and applying a cathodic potential to the oxide via a suitable immersed anode.

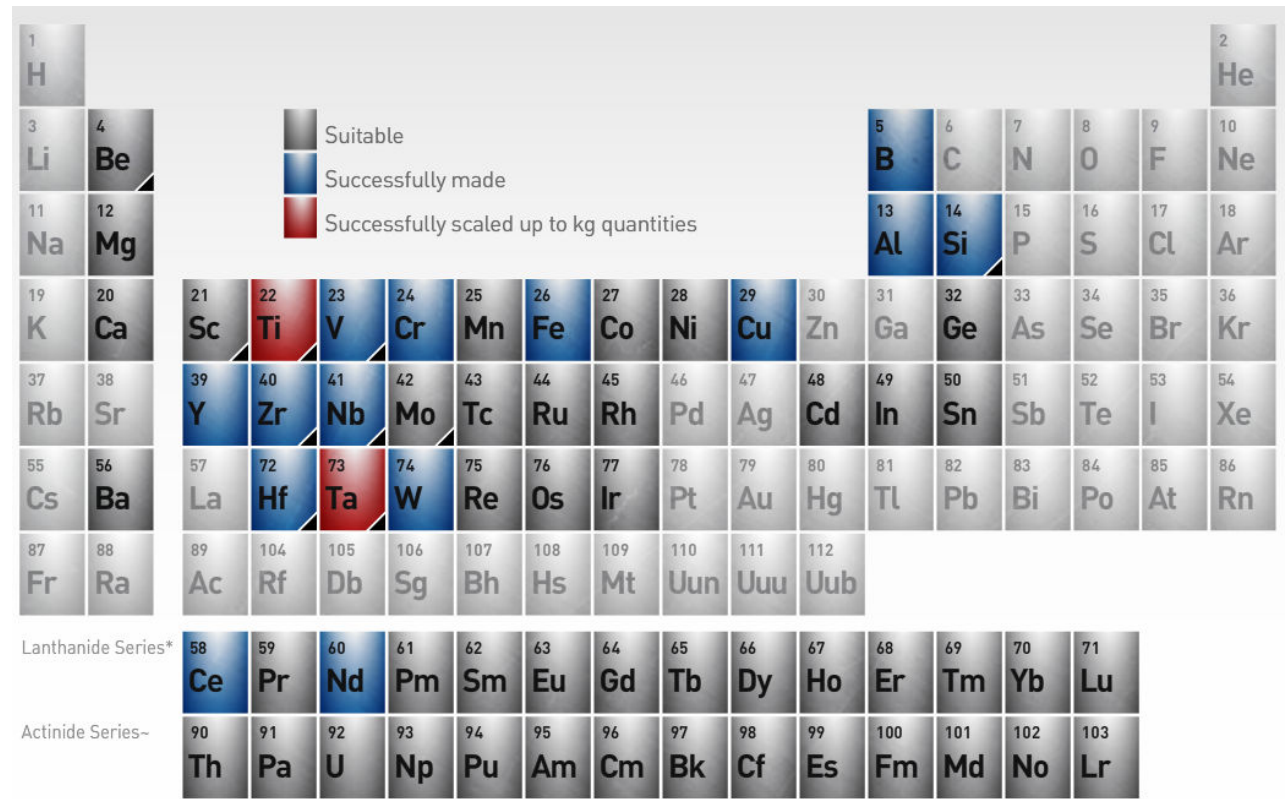

Figure 1: Applicability of the FFC Cambridge Process 
The oxide is normally pressed or extruded and then sintered into a suitable preform shape prior to attachment to the cathode and immersion in the electrolyte. When a voltage of around 3 volts is applied between the electrodes oxygen is stripped from the metal oxide and transported through the electrolyte as an anion which discharges at the anode to form oxygen. Normally, the anode is made of carbon and therefore the oxygen reacts with the carbon to form a mixture of carbon dioxide and carbon monoxide which are evolved and the $\mathrm{CO}$ may be combusted to provide energy. The reduced metal is subsequently washed to remove salt, dried and further post processed as required. A simple schematic of the process is shown in Figure 2.

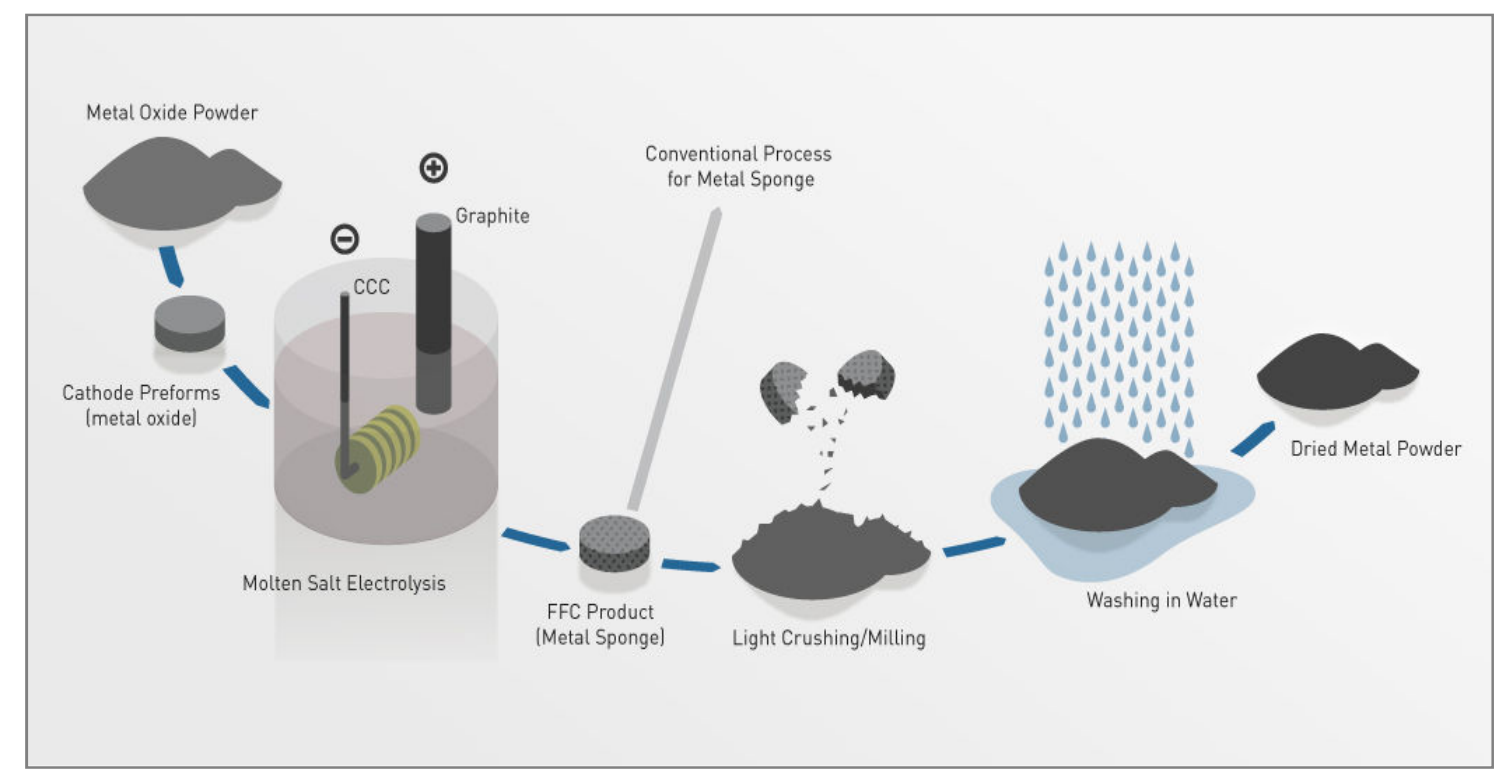

Figure 2: Schematic of the FFC Cambridge Process

Whilst the process is capable of reducing this broad range of metals it is particularly suitable for difficult to reduce metals, for example, tantalum and titanium amongst others. The current incumbent technologies for the production of such metals are typically the Kroll or modified Hunter processes. These have been utilised for the last 60 years or more and are complex, multi-stage, capital intensive and expensive processes with significant environmental impact (Figure 3).

In contrast the FFC process is a much simpler, single stage process that has been calculated to have both lower environmental impact and capital investment cost. The single most striking feature of the FFC process for visitors when they are shown around the facility at Metalysis Limited is its simplicity.

However, in the early years of the discovery of the process many overoptimistic predictions for its future were made. This unrealistic approach to possible commercialisation resulted in eager anticipation followed by disappointment when the predictions were not realised. The current philosophy is to take a much more rigorous and measured approach, recognising the strengths (as well as weaknesses) of the current Kroll process. It is considered that penetration of the titanium market by the FFC process will be progressive with early adoption being for processes where there are significant cost or technical advantages. Such areas are considered to be the powder and resulting near net shape markets. As the technology and scale of manufacture grow it is expected that other areas of the titanium market will progressively open up to the technology. 


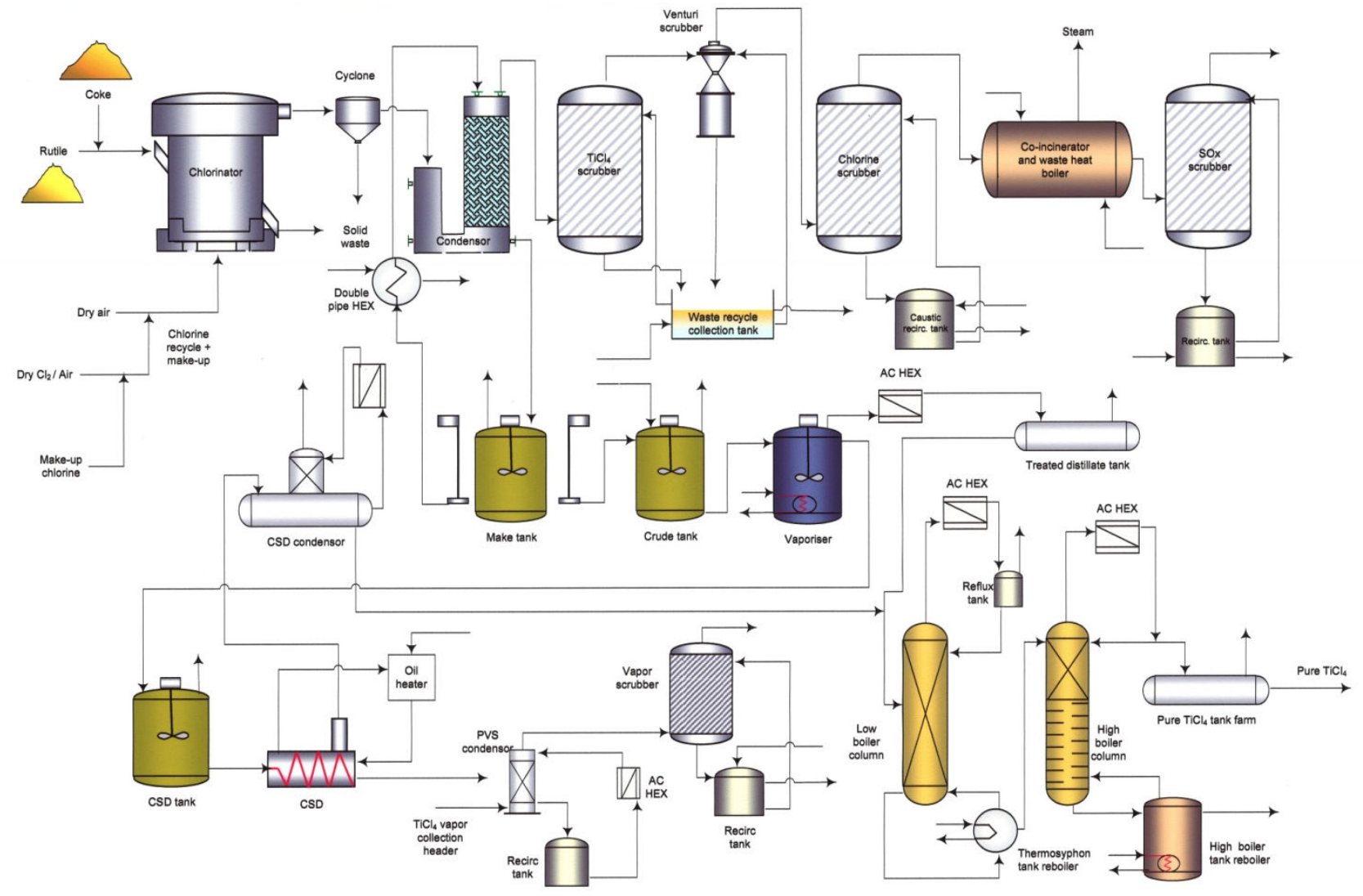

Figure 3: Schematic of the Kroll Process - indicative of its complexity

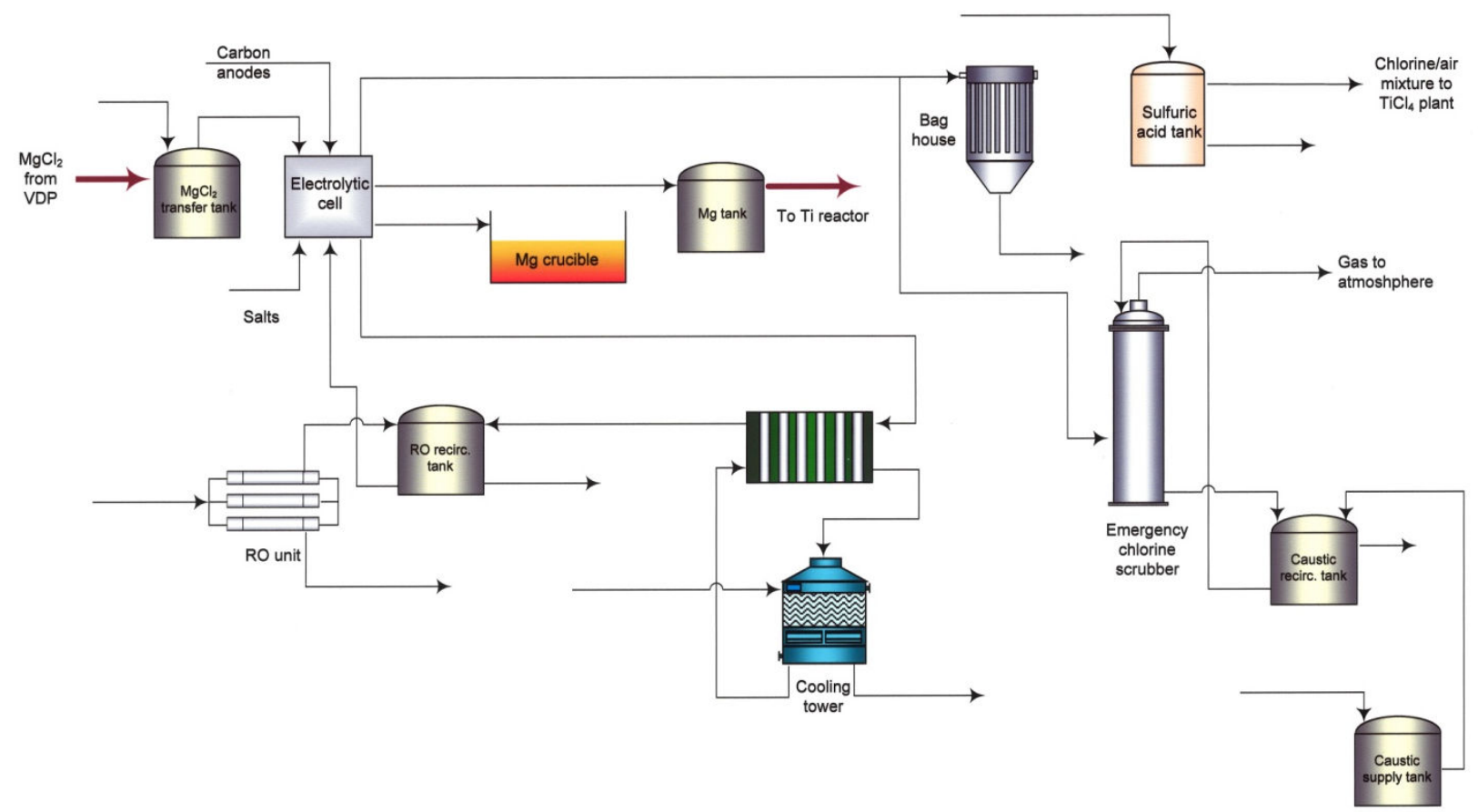

Figure 4: Schematic of the Kroll Process - Magnesium Plant - indicative of its complexity 


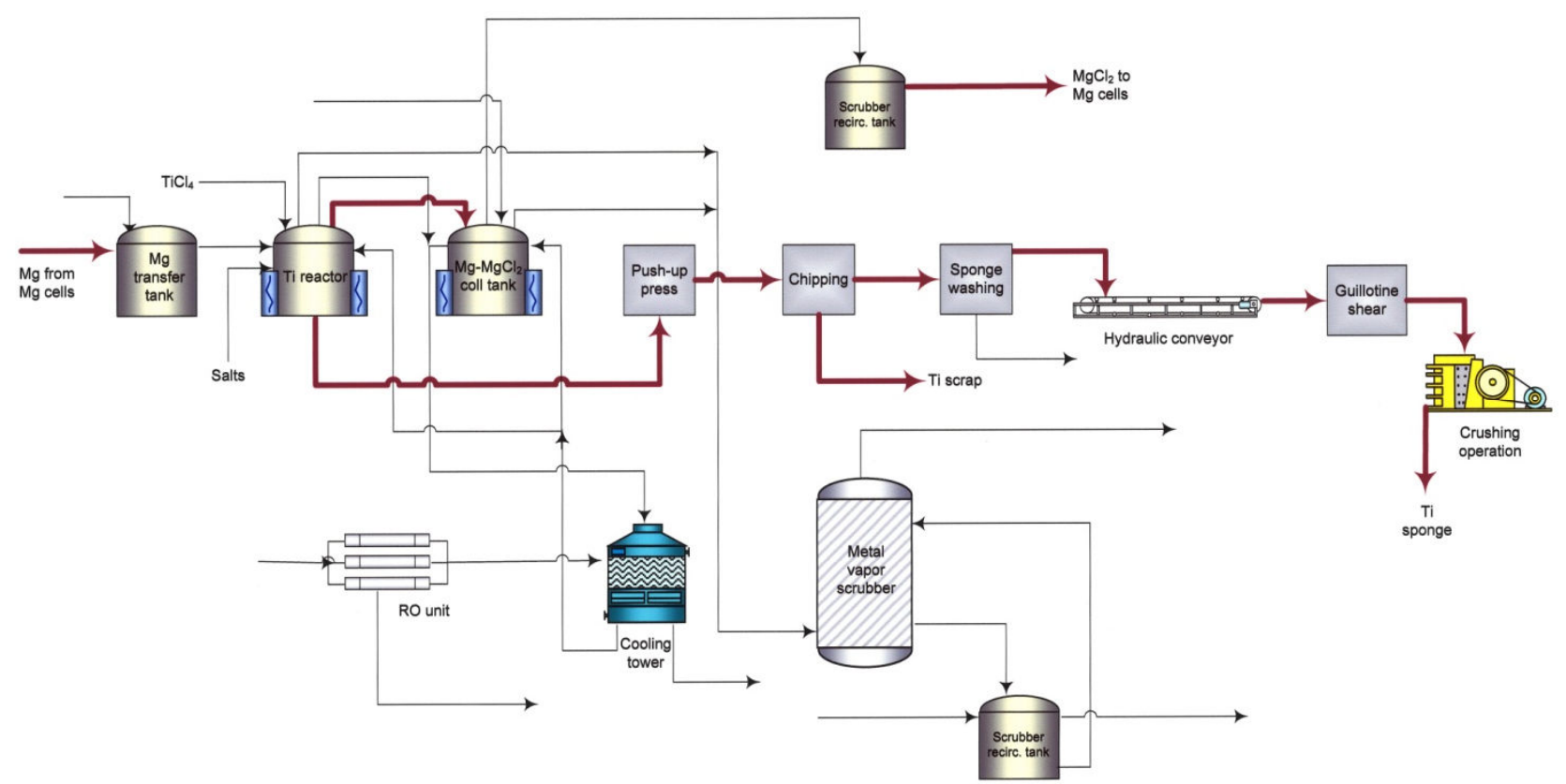

Figure 5: Schematic of the Kroll Process - Magnesium Plant - indicative of its complexity

\section{Current and Future Facilities}

Metalysis Ltd currently has a number of facilities for the FFC process and is constructing a novel design of cell which will be capable of semi-continuous operation. The existing equipment operates in a batch mode. There are 12 laboratory scale cells upon which a mixture of fundamental science and scaled down development experiments are conducted (Figure 4). The equipment has elaborate control, data logging and monitoring systems including a mass spectrometer (Figure 5) for measuring the composition of the process off gases. Whilst these cells reduce only gram quantities of material per run they turn around quickly and operate flexibly and hence are able to generate quantities of scientific data relatively quickly.

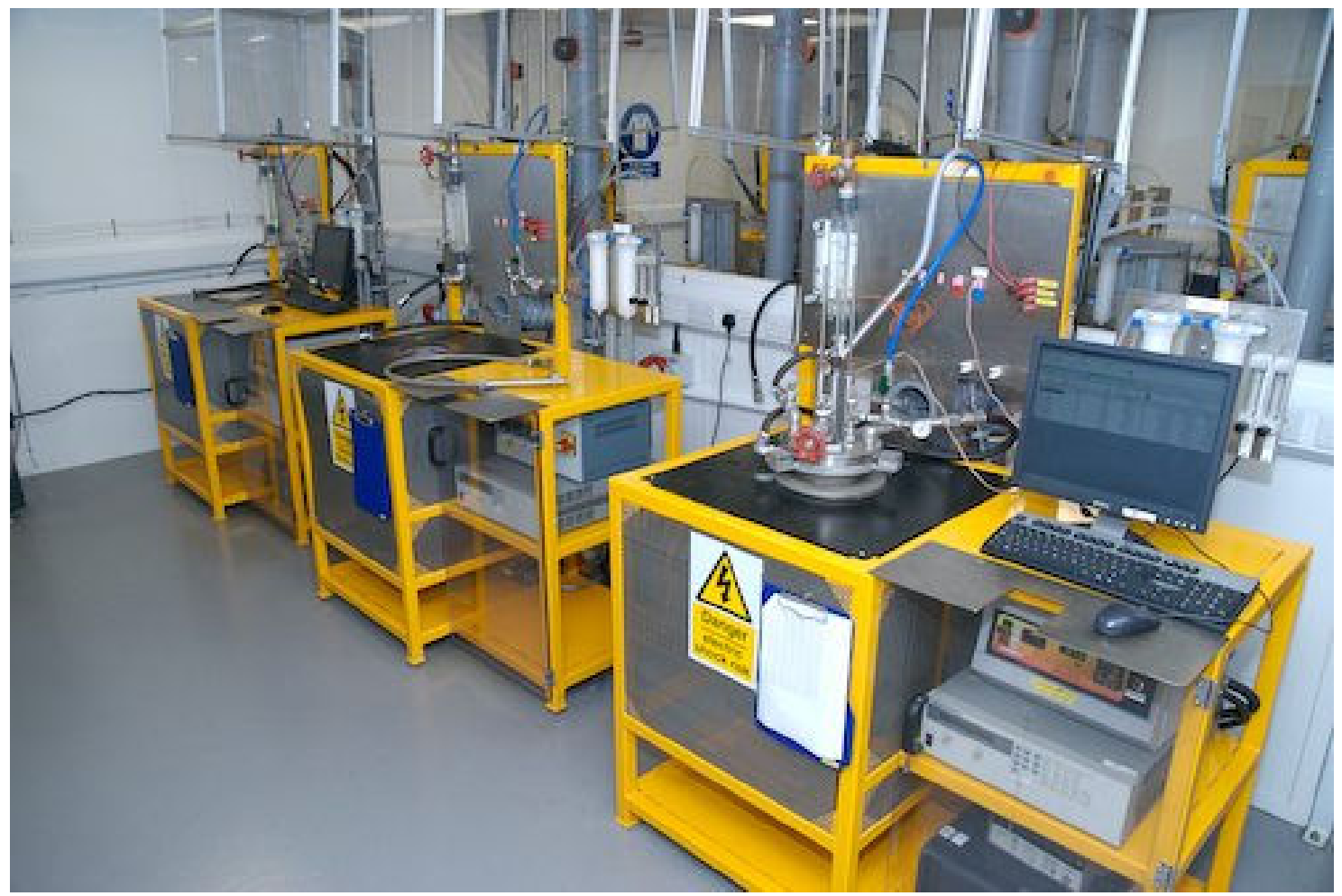

Figure 6: 12 Research and Development scale FFC reduction facilities 


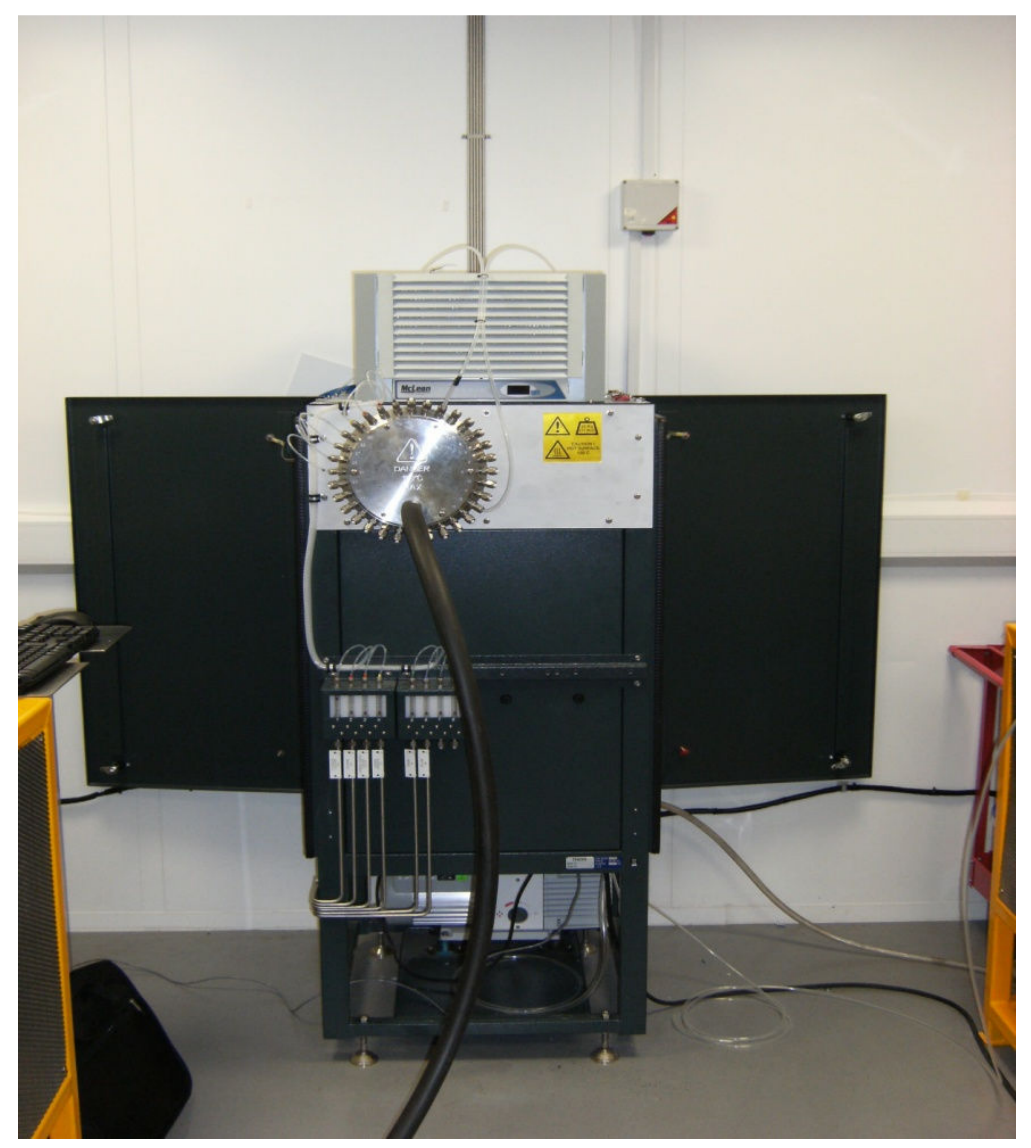

Figure 7: Mass spectrometer used to measure the composition of evolved gases.

The second design of equipment is capable of reducing multi-kilogram quantities of oxide per cycle. There are two of these cells; one is dedicated to tantalum and the other to titanium (Figure 6). These cells function both to provide development data and quantities of FFC reduced product for testing, post processing and customer evaluation. However, like the smaller R\&D cells they operate on a batch process basis and their design is such as to make them unsuitable for commercial production quantities.

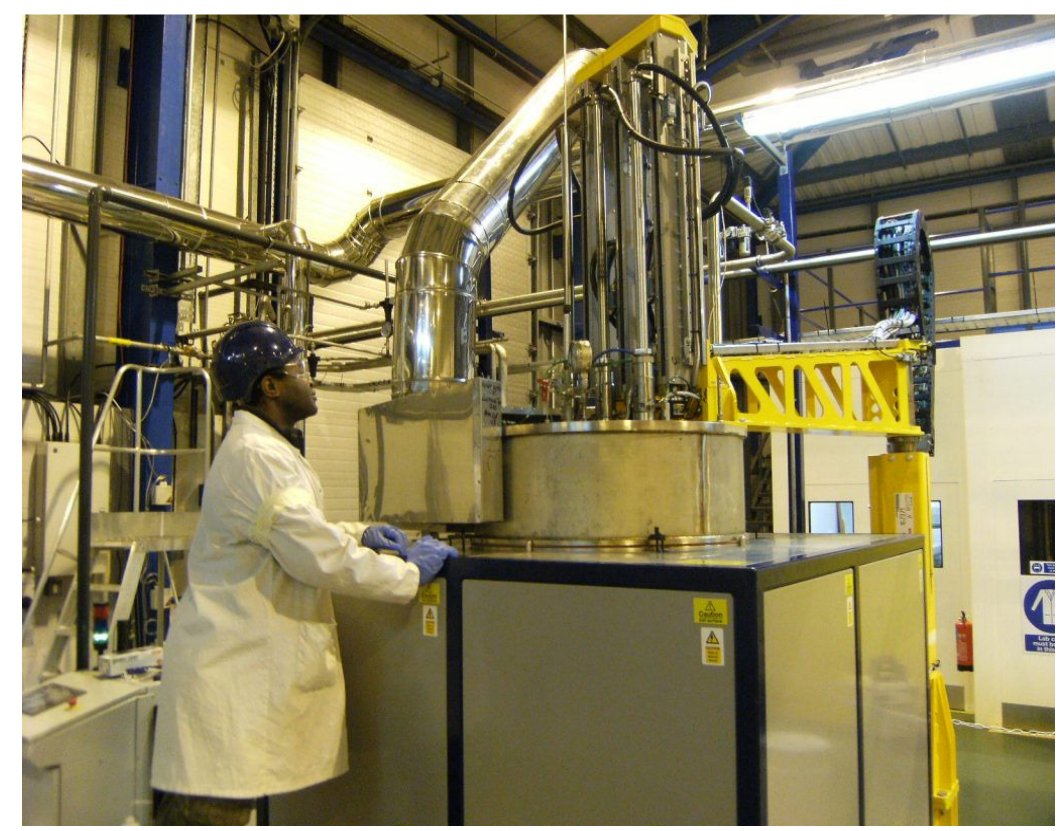

Figure 8: Kilogram scale FFC reduction facility for titanium. 
To address the batch process and other operational and technical limitations of the existing equipment, a novel type of cell has been designed which is the subject of significant new intellectual property including patent applications. The design has been evaluated and refined by small and full scale physical modelling using alternative electrochemical systems. Work has been conducted on the R\&D and development cells to further optimise the design.

Construction of the new cell design is now under way for pre-production scale units to demonstrate the FFC process in semi-continuous operation for Titanium and Tantalum. The design is capable of being scaled up to larger units for commercial production and is modular in design so that additional reduction cells can be readily added as demand for the product increases.

\section{FFC Product}

The FFC product is essentially in the form of a powder which, in the case of titanium, is partially sintered together as a result of the reduction temperature being a significant proportion of its melting temperature $\left(\mathrm{T}_{\mathrm{m} .}=1668^{\circ} \mathrm{C}\right)$. By way of contrast, tantalum with its significantly higher melting point $\left(\mathrm{T}_{\mathrm{m}}=3017^{\circ} \mathrm{C}\right)$ does not sinter significantly and remains a powder.

The chemistry achieved to date is shown in table 1. This chemistry was obtained from a batch of material produced on the multi-kilogram development cell with minimal post processing and it should be noted that there is still significant scope for optimisation of the chemistry in the near term. This is particularly expected to be the case with the commissioning of the new semicontinuous cell.

Table 1: Chemistry of Titanium produced directly by the FFC process at multiple kg scale

\begin{tabular}{|c|c|c|c|c|c|}
\hline & $\begin{array}{c}\text { Oxygen } \\
\text { wt } \%\end{array}$ & Carbon wt\% & Iron wt $\%$ & $\begin{array}{c}\text { Calcium } \\
\text { wt } \%\end{array}$ & $\begin{array}{c}\text { Chlorine } \\
\text { wt } \%\end{array}$ \\
\hline FFC Ti & 0.29 & 0.07 & 0.014 & 0.13 & 0.06 \\
\hline ASTM Gr4 & 0.40 & 0.08 & 0.50 & 0.1 & - \\
\hline
\end{tabular}

A typical reduced product is shown in Figure 7 and in Figure 8 as an SEM image. The sintered nature is apparent from the SEM image.

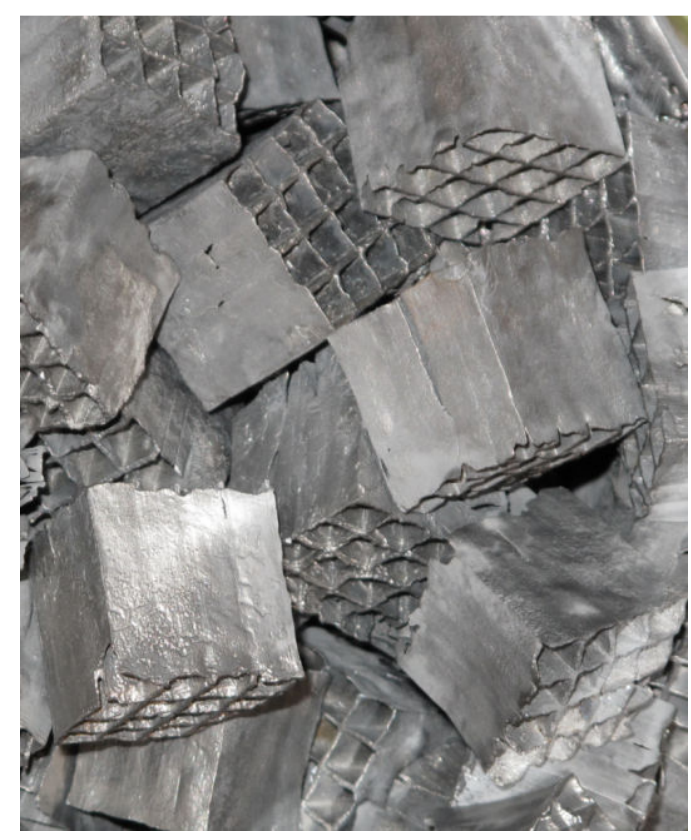

Figure 9: FFC reduced titanium metal as it comes from the cell but following initial light cleaning. 


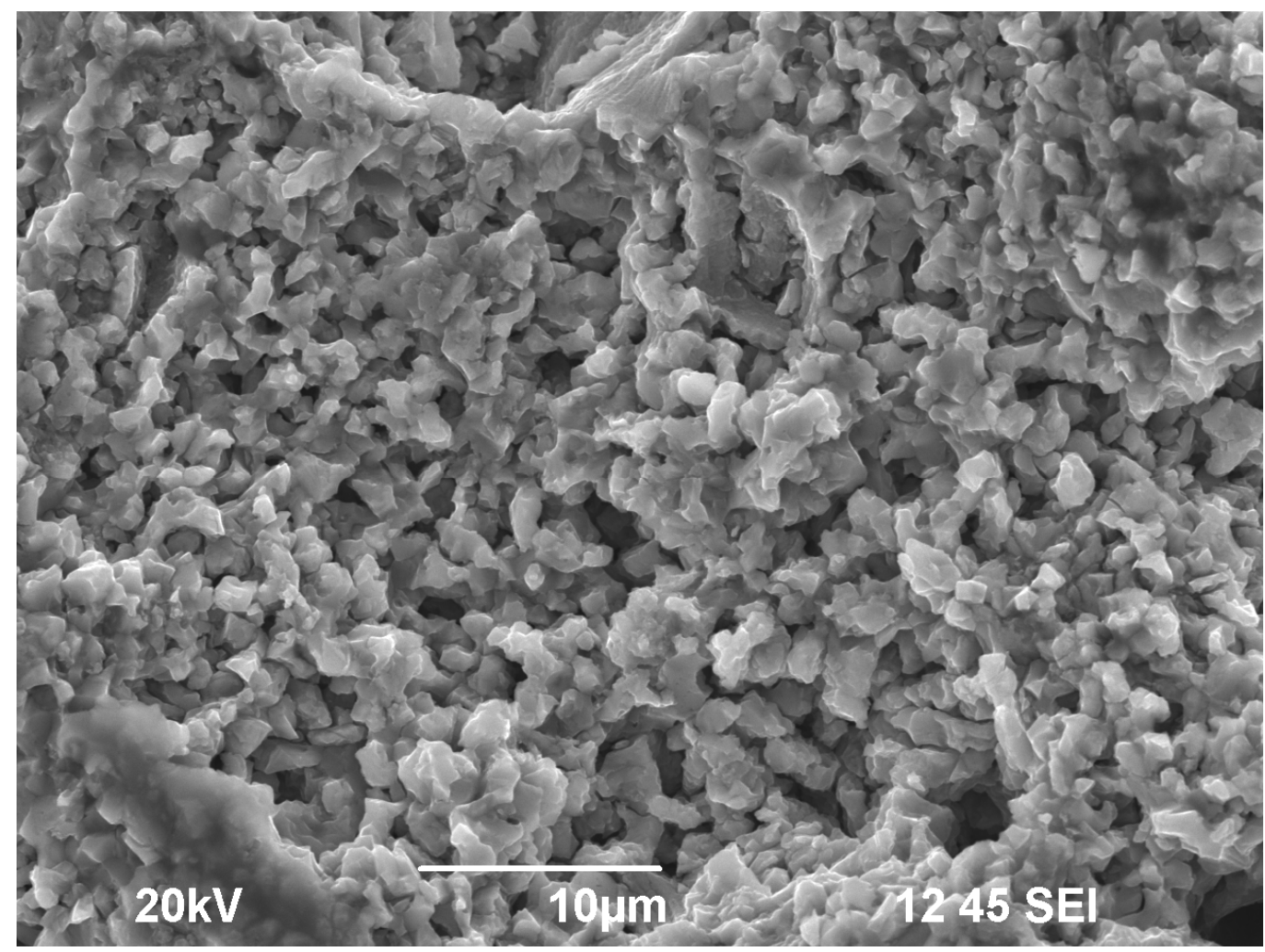

Figure 10: SEM image of the structure of FFC reduced titanium as it comes from the cell but following initial light cleaning.

There are a number of options for the conversion of this product into useful components and these are currently under investigation. One option is to consolidate the product of the FFC process directly to, for example, sheet by roll consolidation. Samples of FFC reduced titanium have been consolidated to sheet in this way and subsequently successfully TIG welded. An example of the compacted and welded product is shown in Figure 9.
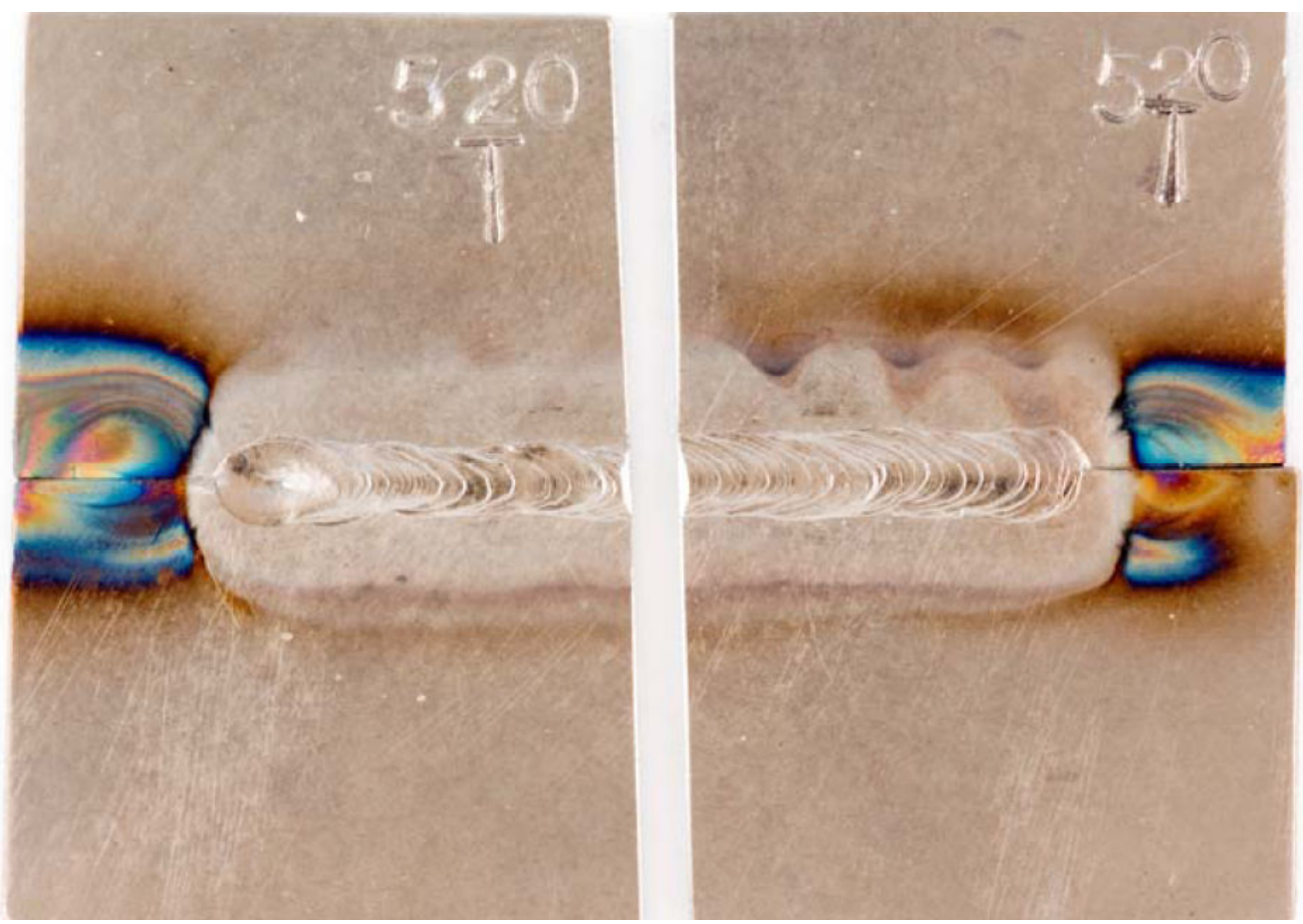

Figure 11: Photograph of FFC roll consolidated and TIG welded CP Titanium sheet. 
The other possible consolidation routes are via conventional powder processes. Powders can be produced from FFC titanium directly by grinding, by hydriding-grinding-dehydriding and by fusion and gas atomisation. Figures 10 to 12 respectively show the structures of FFC Titanium processed in these ways.

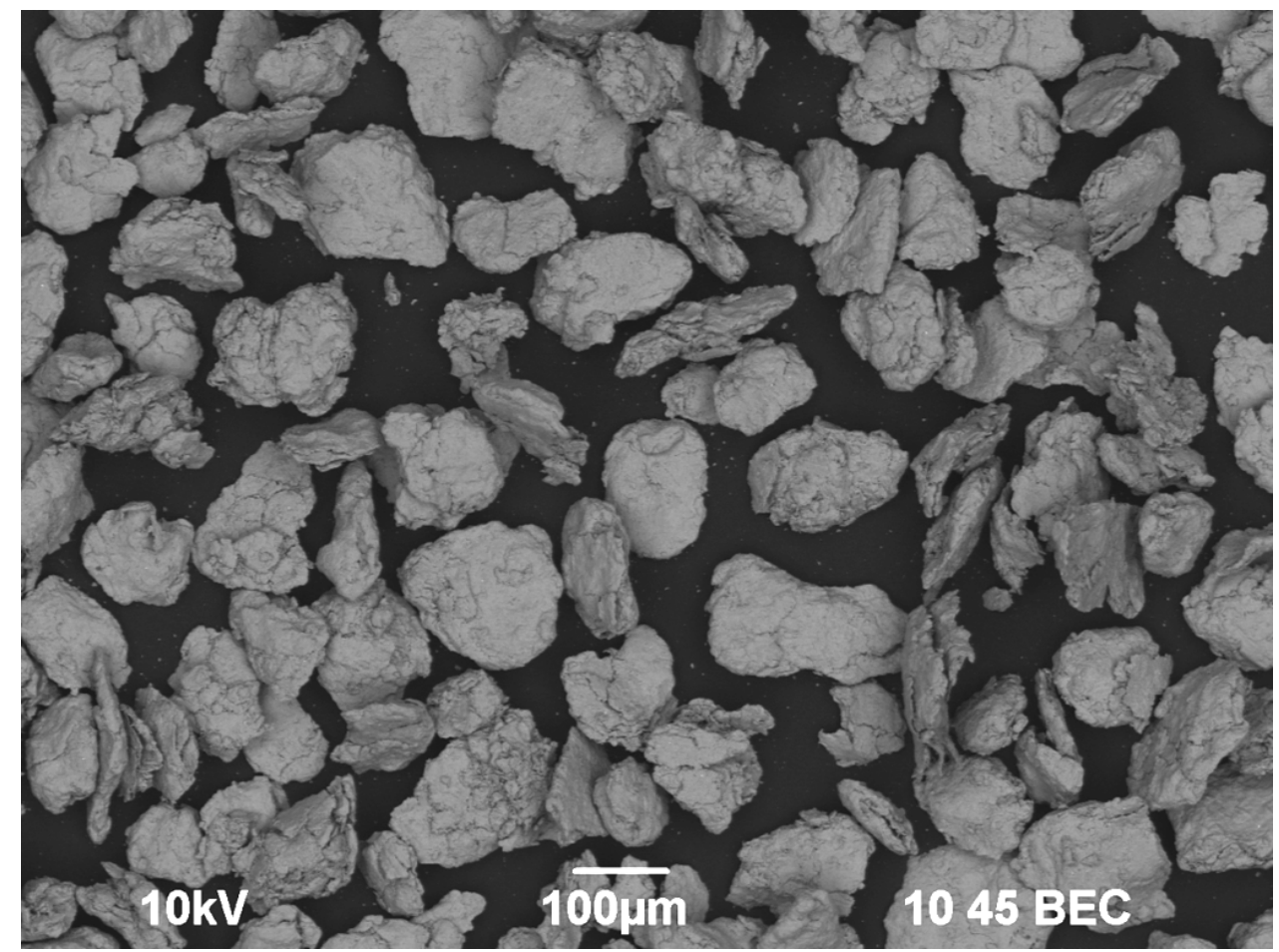

Figure 12: Structure of FFC titanium powder produced by direct grinding of the reduced product.

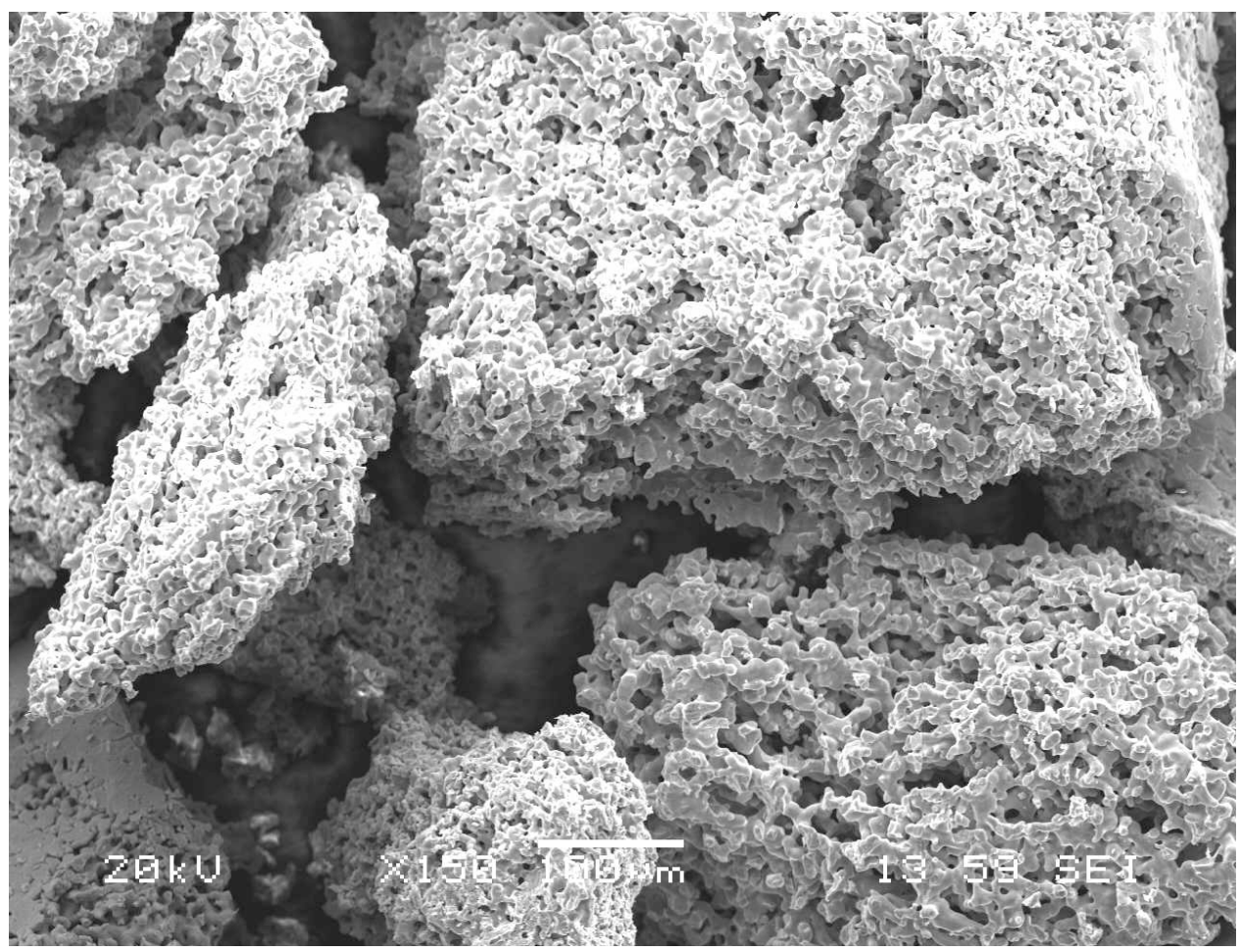

Figure 13: Structure of FFC titanium powder produced by hydride-grind-dehydride of the reduced product. 


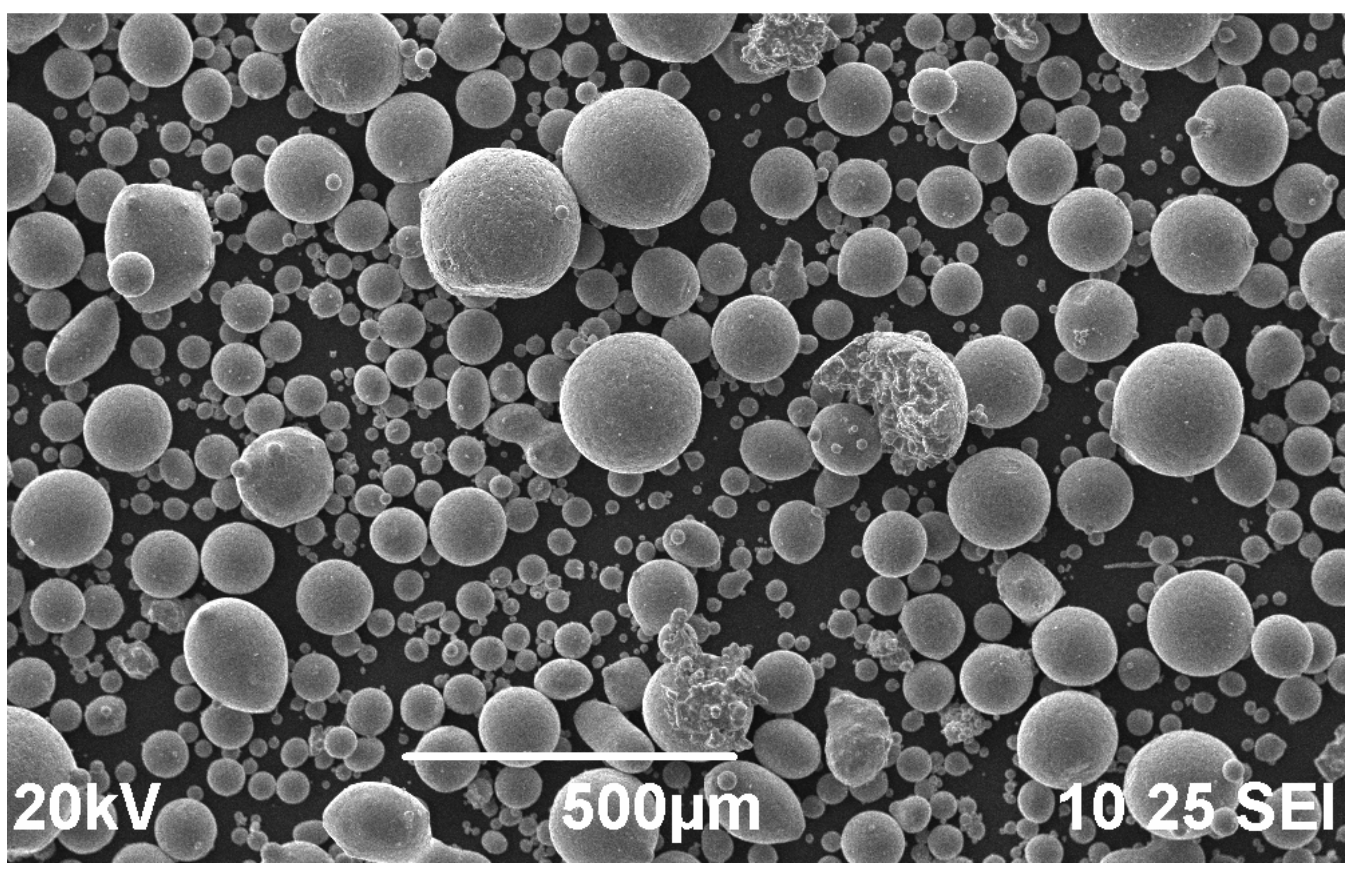

Figure 14: Structure of FFC titanium powder produced by fusion and gas atomisation of the reduced product.

By adopting processing routes using near net shape production, either using powder or direct consolidation of FFC reduced titanium it is considered that significant cost benefits may be achieved compared to conventional Kroll sponge-ingot metallurgy-mill product type routes. In addition the anticipated much lower capital cost and modular nature of an FFC titanium facility compared to a Kroll plant adds further benefits.

\section{Conclusions}

1. It is considered that the early adoption of the FFC process will be for near net shape manufacture, in particular powder metallurgy products.

2. FFC titanium can be successfully consolidated directly to sheet that can be welded using a conventional TIG process.

3. FFC titanium can be readily converted to powder by a variety of techniques, the choice of which is dependent on the end application.

4. The process is considered to be able to provide a low capital and production through cost alternative to the Kroll process for powder route products. It also has the benefit of being scalable to meet demand.

\section{Future Work}

The following future work is planned for the FFC process:

1. Process and post process development and optimisation.

2. Scale up and demonstration of a semi-continuous cell that is currently under construction.

3. Develop a route for Ti alloys, in particular Ti-6Al-4V by direct reduction in the FFC cell.

4. Commercialisation by engagement with customers and titanium related industry. 